\title{
Mediterranean Diet Score: Associations with Metabolic Products of the Intestinal Microbiome, Carotid Plaque Burden, and Renal Function
}

\author{
Michael Pignanelli ${ }^{1}$, Caroline Just ${ }^{2}$, Chrysi Bogiatzi ${ }^{3,4}$, Vincent Dinculescu ${ }^{5}$, \\ Gregory B. Gloor ${ }^{6}$, Emma Allen-Vercoe ${ }^{7}$, Gregor Reid ${ }^{8}$, Bradley L. Urquhart ${ }^{9}$, \\ Kelsey N. Ruetz ${ }^{9}$, Thomas J. Velenosi ${ }^{9}$ and J. David Spence ${ }^{3,10, *(1)}$
}

1 Schulich School of Medicine and Dentistry M.D. Candidate (CIHR Summer Research Training Program), London, ON N6A 3K7, Canada; mpignanelli2018@meds.uwo.ca

2 Division of Neurology, Schulich School of Medicine and Dentistry, Western University, London, ON N6A 3K7, Canada; cjust2@uwo.ca

3 Stroke Prevention \& Atherosclerosis Research Centre, Robarts Research Institute, Western University, 1400 Western Road, London, ON N6G 2V4, Canada; chrysi.bogiatzi@medportal.ca

4 Current address: Department of Neurology, McMaster University, Hamilton, ON L8S 4K1, Canada

5 Department of Radiology, University of Calgary, Calgary, AB T2N 4N1, Canada; Vince.Dinculescu@uottawa.ca

6 Department of Biochemistry, Schulich School of Medicine and Dentistry, Western University, London, ON N6A 5C1, Canada; ggloor@uwo.ca

7 Department of Molecular and Cellular Biology, University of Guelph, Guelph, ON N1G 2W1, Canada; eav@uoguelph.ca

8 Departments of Urology and Microbiology, Schulich School of Medicine and Dentistry, Western University, London, ON N6A 5C1, Canada; gregor@uwo.ca

9 Departments of Physiology \& Pharmacology, Schulich School of Medicine and Dentistry Western University, London, ON N6A 3K7, Canada; burquha2@uwo.ca (B.L.U.); Kruetz2@uwo.ca (K.N.R.);

Tvelenosi@gmail.com (T.J.V.)

10 Divisions of Neurology and Clinical Pharmacology, Western University, London, ON N6A 5A5, Canada

* Correspondence: dspence@robarts.ca; Tel.: +1-519-931-5731; Fax: +1-519-931-5737

Received: 29 April 2018; Accepted: 14 June 2018; Published: 16 June 2018

\begin{abstract}
Metabolic products of the intestinal microbiome such as trimethylamine N-oxide (TMAO) that accumulate in renal failure (gut-derived uremic toxins, GDUTs) affect atherosclerosis and increase cardiovascular risk. We hypothesized that patients on a Mediterranean diet and those consuming lower amounts of dietary precursors would have lower levels of GDUTs. Patients attending vascular prevention clinics completed a Harvard Food Frequency Questionnaire (FFQ) and had plasma levels of TMAO, p-cresylsulfate, hippuric acid, indoxyl sulfate, p-cresyl glucuronide, phenyl acetyl glutamine, and phenyl sulfate measured by ultra-performance liquid chromatography coupled to quadrupole time-of-flight mass spectrometry. Carotid plaque burden was measured by ultrasound; CKD-Epi equations were used to estimate the glomerular filtration rate. In total, 276 patients completed the study. Even moderate renal function significantly increased plasma GDUTs, which were significantly associated with higher carotid plaque burden. There was no significant difference in plasma levels of any GDUT associated with a Mediterranean diet score or with intake of dietary precursors. In omnivorous patients with vascular disease, the intake of dietary precursors of intestinal metabolites or adherence to a Mediterranean diet did not change plasma GDUT. Approaches other than diet, such as probiotics and repopulation of the intestinal microbiome, may be required to mitigate the adverse effects of GDUTs.
\end{abstract}

Keywords: intestinal microbiome; metabolites; Mediterranean diet; TMAO; carotid plaque; renal function 


\section{Introduction}

The role of the intestinal microbiome in human health [1], and interactions between the diet, the intestinal microbiome, and vascular disease [2], as well as chronic kidney disease (CKD) [3] have become increasingly apparent in recent years. Trimethylamine is naturally abundant in fish [4]; it is also produced by intestinal bacteria from carnitine (largely from red meat) and phosphatidylcholine (largely from egg yolk). Trimethylamine is then oxidized in the liver to trimethylamine n-oxide (TMAO) $[5,6]$. In animal models, TMAO causes atherosclerosis [5]. In patients referred for coronary angiography, levels of TMAO after a test dose of two hard-boiled eggs significantly predicted cardiovascular risk: patients in the top quartile of TMAO levels had a 2.5-fold increase in the three-year risk of stroke, myocardial infarction, or vascular death [7].

One of the most intriguing aspects of this case is that the production of TMAO was affected by diet. When carnitine was given to meat-eaters, they produced TMAO; however, vegans given carnitine did not [6]. This suggests that modification of diet to reduce production of intestinal microbiome metabolic products may be a way to reduce cardiovascular risk. Another important aspect of this issue is that the plasma intestinal microbiome metabolites are renally excreted, so in renal failure, blood levels are high. High levels of TMAO accelerate decline of renal function and are associated with increased cardiovascular risk [8]. In patients with CKD, plasma levels of indoxyl sulfate (IS) and p-cresyl sulfate (PCS) are 54 and 17 times higher, respectively, than in healthy individuals [9]. Although protein binding is low, concentrations of phenylacetylglutamine concentrations are $>100$-fold higher in patients with end stage kidney disease [10].

Metabolic products of the intestinal microbiome, such as p-cresyl sulfate from tyrosine and phenylalanine, have been shown to be markers of abnormal microbiota present in the human intestine. P-cresyl sulfate (PCS) accelerates atherosclerosis and renal impairment by increasing oxidative stress and is associated with cardiovascular risk in relation to renal impairment. Other metabolic products of the intestinal microbiome, including phenylacetylglutamine, indole 3-acetic acid, p-cresyl sulfate, indoxyl sulfate, and p-cresyl glucuronide also accelerate cardiovascular disease in renal failure [11-14] Indoxyl sulfate and indole 3-acetic acid, derived from microbial metabolism of tryptophan, promote oxidative stress and endothelial dysfunction [15] and are associated with vascular stiffness, aortic calcification, and cardiovascular mortality in hemodialysis patients [11,16].

The Mediterranean diet is thought to be beneficial because it involves a high intake of fiber, vitamins, and antioxidants [17]. It appears that the eating pattern is what matters, as supplementation with individual vitamins and antioxidants does not appear to have as great an effect on cardiovascular risk as the Mediterranean diet.

In this study we assessed the intake of specific nutrient precursors and also the effect of Mediterranean diet scores on the plasma levels of seven intestinal microbiome metabolic products. As a "mainly vegetarian diet" [18], the Cretan Mediterranean diet would be expected to lower levels of all the intestinal metabolites we measured, since the components are derived from amino acids, carnitine, or choline. We also studied the association of renal function with plasma levels of the metabolites, and carotid plaque burden in relation to plasma levels of the metabolites and the Mediterranean diet score. We hypothesized that a low intake of specific nutrients and high Mediterranean diet scores would be associated with lower plasma levels of the metabolites and less of a carotid plaque burden.

\section{Methods and Materials}

\subsection{Study Population}

Patients enrolled in the study were identified from the clinical database of the Stroke Prevention and Atherosclerosis Research Centre, Robarts Research Institute, Western University, London, Ontario, 
Canada. Patients in the database were from one of several clinics at the University Hospital, London, Ontario, Canada: the Stroke Prevention Clinic, the Urgent Transient Ischemic Attack (TIA) Clinic, and the Premature Atherosclerosis Clinic. All patients were advised at the time of their first referral and at follow-up visits to follow a diet similar to the Mediterranean diet, counseled on how to achieve this, and given a recipe booklet with many websites listed where they could obtain additional recipes. They were advised to consume only whole grains, seldom consume red meat (e.g., once a month), use olive oil and replace butter with non-hydrogenated canola/olive oil margarine, consume a high intake of vegetables, fruits and legumes (e.g., lentils, beans, nuts, peas, chickpeas), and keep intake of animal flesh (mainly fish and chicken) to $\sim 2$ ounces daily or a serving the size of the palm of the hand every other day, avoiding egg yolks and limiting red meat. The recipe booklet is available for download from [19]. No patients received monetary compensation for participation in the study. They were recruited for a study of the intestinal microbiome in extremes of atherosclerosis [20] from a sample of 3056 patients with all data required to calculate residual scores in a regression model, in order to identify outliers with atherosclerosis not explained by traditional risk factors [20]. In that study 316 patients were recruited; in this paper we report the results of nutrient analyses for the 276 patients who completed the dietary assessment, as described below. Patients were enrolled between 2014 and 2016. The size of the study population was determined by funding available.

\subsection{Dietary Assessment}

Food intake over the past year was assessed using the blue 131-item self-reported and semi-quantitative Harvard Food Frequency Questionnaire (FFQ DA 80), which has been extensively validated [21,22]. As described previously, respondents were asked to select one of nine levels for each standardized food item, based on average frequency of consumption in the past year [23]. The nine options ranged from "never, or less than once per month" to "six or more times per day". For evaluation of each nutrient, FFQ scores were converted into estimated physical quantity consumed. Using an approach outlined previously, the estimated number of servings per day was multiplied by standard serving size for each food [24].

Unless otherwise indicated, average nutrient intake was calculated by multiplying nutrient values (by mass) from the Harvard University Food Composition Database and the USDA National Nutrient Database for Standard Reference $[23,25,26]$. Results from each source of a particular nutrient were added to represent estimated total intake for specific nutrients. Total energy (in kcal) was determined using an analogous approach. Except for the estimation of free L-carnitine from diet, nutrient and energy coding was performed at the Channing School of Public Health.

\subsection{Diet Patterns and Nutrient Scores}

Adherence to the prescribed Mediterranean diet (associated with lower risk of incident CVD and stroke) was assessed by generating adherence to Mediterranean (aMED) diet scores from the FFQ [26,27]. The FFQ was administered at the time of enrolment in the study. Briefly, the aMED score is a composite score composed of an individual's sum of specific items in a food group compared to the median of the summed frequency for the same food group. Food groups used to generate the aMED score included vegetables (excluding potatoes), fruits, nuts and seeds, red and processed meats, whole grains and plain cereals, fish, monounsaturated to saturated fat ratio, and ethanol intake. A score closer to eight represented greater adherence to the Mediterranean diet, whereas a score of 0 represented the lowest possible score. Patient intake of items from food groups associated with positive health outcomes received a score of 1 if their intake was above the median for that food group. Only red and processed meat intake received a 0 if patient intake surpassed the median intake of the sample. We also assigned 1 point for alcohol intake between 5-15 g/day, representing one 12 oz can of non-light beer, $5 \mathrm{oz}$ of wine, or $1.5 \mathrm{oz}$ liquor. 


\subsection{Total Protein, Amino Acids, Fiber and TMAO Precursors Including L-carnitine}

Total protein and amino acids consumed per day were determined by summation of their density in each item on the FFQ as described above. Total indigestible fiber determination was accomplished using biochemical and/or enzymatic methods approved by the Association of Analytic Communities (AOAC) [28]. Total choline-containing nutrients included the sum of water-soluble choline-containing compounds (free choline, glycerophosphocholine, phosphocholine), lipid membrane-associated choline (phosphatidylcholine, sphingomyelin), and total betaine (without supplementation).

The following items from the FFQ were used to estimate total free L-carnitine: "chicken sandwich", "chicken without skin", “chicken liver", "liver", “bacon", “extra-lean hamburger", "hamburger", "pork", "beef or lamb as a main dish", "tuna", "shrimp", "dark oily fish" [29]. Although not exhaustive for all sources of L-carnitine, these entries were selected because meat products are the most important sources of L-carnitine in human diets [30]. Concentrations of free L-carnitine in individual food items were estimated using values published by Demarquoy et al. [31], and online from the Linus Pauling Institute micronutrient database at Oregon State University [31,32,32]. Total trimethylamine precursor nutrients were calculated as the sum of choline-containing nutrients and L-carnitine intake per day.

\subsection{Biochemical Methods}

Plasma samples were obtained after an overnight fast at enrollment; after centrifugation they were stored at $-80{ }^{\circ} \mathrm{C}$ until they were transported on dry ice to the biochemical laboratory. Metabolites produced by the intestinal microbiome were measured by ultra-performance liquid chromatography (UPLC) coupled to quadrupole time-of-flight mass spectrometry (QToF/MS), as previously described [20].

TMAO was determined by hydrophilic interaction liquid chromatography using methods similar to those previously published [33,34]. In brief, plasma proteins were precipitated with the addition of ice-cold acetonitrile (containing $10 \mu \mathrm{M}$ betaine- $\mathrm{d} 3$ as internal standard) at a ratio of 4:1 acetonitrile:plasma. Addition of the acetonitrile containing betaine-d3 internal standard occurred prior to sample extraction. Following centrifugation, samples were concentrated 10-fold by evaporating the supernatant and reconstituting in acetonitrile. Reconstituted samples were transferred to vials and $10 \mu \mathrm{L}$ were injected onto a Waters ACQUITY BEH Amide column (Waters Canada, Mississauga, ON, Canada) $(1.7 \mu \mathrm{m}, 2.1 \times 100 \mathrm{~mm})$. The mobile phases used for the analysis were $5 \mathrm{mM}$ ammonium formate $\mathrm{pH} 3.5$ (A) and acetonitrile (B), delivered in a gradient at a flow rate of $0.45 \mathrm{~mL} / \mathrm{min}$ [34]. TMAO was measured by positive electrospray ionization and the Waters Xevo G2-S instrument for QToF/MS was operated in sensitivity mode. The $2 \mathrm{M} \pm \mathrm{H}$ ion $(151.1446 \mathrm{~m} / \mathrm{z})$ was monitored for quantification of TMAO and the $\mathrm{M} \pm \mathrm{H}$ ion $(121.1056 \mathrm{~m} / z)$ of internal standard betaine-d 3 was monitored. Data were acquired in centroid mode with scans every $0.1 \mathrm{~s}$. Accurate mass was confirmed using leucine-enkephalin $(1 \mathrm{ng} / \mu \mathrm{L})$ as a lockspray infused at a flow rate of $10 \mu \mathrm{L} / \mathrm{min}$ and scans acquired every $10 \mathrm{~s}$.

All other metabolites (p-cresyl sulfate, p-cresyl glucuronide, indoxyl sulfate, hippuric acid, phenylacetylglutamine, and phenyl sulfate) were measured using reversed phase chromatography as previously described [35]. Briefly, plasma proteins were precipitated by adding acetonitrile (containing $2.5 \mu \mathrm{M}$ chlorpropamide as internal standard) in a ratio of 3:1 acetonitrile:plasma. Addition of the acetonitrile containing chlorpropamide internal standard occurred prior to sample extraction. Samples were centrifuged, and the supernatant was diluted 5-fold in water. Samples were transferred to vials and $1 \mu \mathrm{L}$ was injected onto a Waters ACQUITY HSS T3 column $(1.8 \mu \mathrm{m}, 2.1 \times 100 \mathrm{~mm})$. The mobile phases used were water (A) and acetonitrile (B) both containing $0.1 \%$ formic acid, delivered at a flow rate of $0.45 \mathrm{~mL} / \mathrm{min}$. Column temperature was $45^{\circ} \mathrm{C}$. Metabolites were measured on a Waters Xevo G2-S apparatus for QToF/MS by negative electrospray ionization operating in resolution mode. The $\mathrm{M}-\mathrm{H}$ ion for each metabolite was monitored: $\mathrm{p}$-cresyl sulfate $(187.0065 \mathrm{~m} / \mathrm{z})$, p-cresyl glucuronide $(283.0822 \mathrm{~m} / \mathrm{z})$, indoxyl sulfate $(212.0018 \mathrm{~m} / \mathrm{z})$, hippuric acid $(178.0503 \mathrm{~m} / \mathrm{z})$, phenylacetylglutamine $(263.1032 \mathrm{~m} / \mathrm{z})$, and phenyl sulfate $(172.9908 \mathrm{~m} / \mathrm{z})$. Data were acquired in centroid mode with scans 
every $0.1 \mathrm{~s}$. Accurate mass was confirmed using leucine-enkephalin $(1 \mathrm{ng} / \mu \mathrm{L})$ as a lockspray infused at a flow rate of $10 \mu \mathrm{L} / \mathrm{min}$ and scans acquired every $10 \mathrm{~s}$. Inter and intra-day precision for all metabolites was less than $15 \%$. Figure 1 shows a representative chromatogram.

A

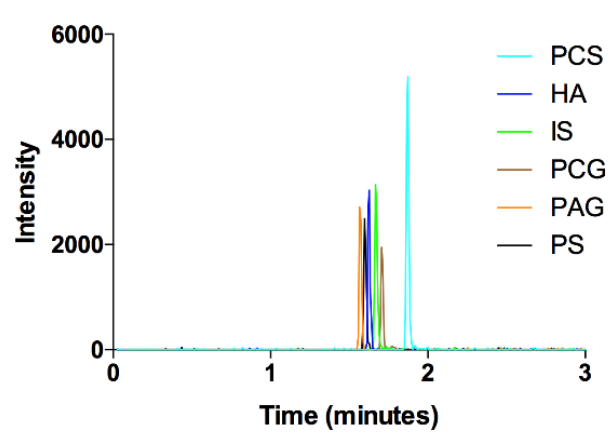

B

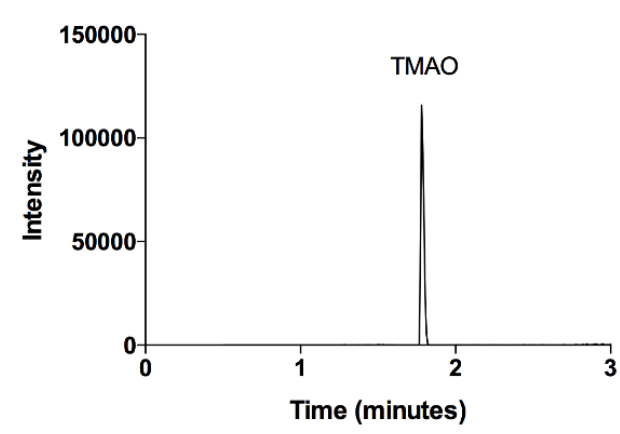

Figure 1. Representative chromatograms of metabolites of the intestinal microbiome. (A) Extracted ion chromatograms for p-cresyl sulfate (PCS), hippuric acid (HA), indoxyl sulfate (IS), p-cresyl glucuronide (PCG), phenylacetylglutamine (PAG), and phenyl sulfate (PS) were overlaid. These metabolites were measured using reverse phase liquid chromatography. (B) Extracted ion chromatogram of trimethylamine $\mathrm{N}$-oxide (TMAO) which was measured by hydrophilic interaction liquid chromatography.

Serum creatinine, total cholesterol, triglycerides, HDL cholesterol and LDL cholesterol were measured in the Biochemistry lab of the London Health Sciences Centre by routine methods. Renal function was estimated by the Chronic Kidney Disease Epidemiology Collaboration (CKD-Epi) equations.

\subsection{Ethics}

Participants gave written informed consent to an ethics protocol approved by the Western University Health Sciences Research Ethics board (approval number 12107E).

\subsection{Statistical Methods}

Metabolites produced by the intestinal microbiome were divided into quintiles, and nutrient intakes compared by quintile of metabolites with analysis of variance. Post hoc testing was performed using Tukey's b test. Mediterranean diet scores were divided into quartiles or tertiles and compared by analysis of variance. These choices were made based on inspection of the data. Baseline characteristics of the study population were characterized as mean, SD for continuous variables and $n$, \% for categorical variables. Statistical analyses were performed using SPSS (version 24, IBM Corporation, Armonk, NY, USA).

\section{Results}

The FFQ was completed by 276 study participants. Table 1 shows the patient characteristics; they were typically middle-aged/elderly high-risk vascular patients with reasonably well-controlled risk factors. The carotid plaque burden was very high $\left(186.06 \pm 221.84 \mathrm{~mm}^{2}\right)$, which is in the top quartile of total plaque area in our clinic population, with a $19.5 \%$ five-year risk of stroke, myocardial infarction, or vascular death after adjustment for risk factors [36].

\subsection{Components of the Mediterranean Diet Score}

Table 2 shows the intake of the components of the Mediterranean diet score quintile of the aMed score. Except for alcohol, there were significant differences of the intake of all the other components. 
Table 1. Characteristics of the study population. $n=276$.

\begin{tabular}{lccc}
\hline Continuous Variables & Mean & SD & Range \\
\hline Age (years) & 66.87 & 10.45 & $40-91$ \\
Body mass index $\left(\mathrm{kg} / \mathrm{M}^{2}\right)$ & 28.49 & 6.08 & $17.1-68.5$ \\
Systolic blood pressure $(\mathrm{mmHg})$ & 143.27 & 21.29 & $103-221$ \\
Diastolic blood pressure $(\mathrm{mmHg})$ & 84.11 & 12.20 & $53-142$ \\
Total cholesterol $(\mathrm{mmol} / \mathrm{L})$ & 4.75 & 1.14 & $2.03-8.12$ \\
Triglycerides & 1.76 & 1.07 & $0.37-7.33$ \\
HDL-C $(\mathrm{mmol} / \mathrm{L})$ & 1.33 & 0.41 & $0.44-3.43$ \\
LDL-C $(\mathrm{mmol} / \mathrm{L})$ & 2.61 & 1.01 & $0.58-5.86$ \\
eGFR CKD-Epi & 75.95 & 19.73 & $6.43-112.54$ \\
Total plaque area $\left(\mathrm{mm}^{2}\right)$ & 186.06 & 221.84 & $0-975$ \\
\hline Categorical variables & $n$ & $\%$ & \\
Male & 164 & $59.4 \%$ & \\
Diabetic & 53 & $19.2 \%$ & \\
\hline Smoker & & & \\
Never & 105 & $38.0 \%$ & \\
Quit & 153 & $55.4 \%$ & \\
Still smoking & 18 & $6.5 \%$ & \\
\hline
\end{tabular}

Table 2. Components of the Mediterranean diet score. All components are shown as grams per day except for the ratio of monounsaturated to saturated fats.

\begin{tabular}{ccccccc}
\hline & \multicolumn{7}{c}{ Quintiles of the Mediterranean Diet Score } \\
\hline Quintile & $\mathbf{Q 1}$ & $\mathbf{Q 2}$ & $\mathbf{Q 3}$ & $\mathbf{Q 4}$ & $\mathbf{Q 5}$ & $\boldsymbol{p}$ Value * \\
Score & $<\mathbf{2}$ & $\mathbf{2 - 4}$ & $\mathbf{4}$ & $\mathbf{5}$ & $\mathbf{6}$ & 0.78 \\
Alcohol (g) & $9.45 \pm 14.66$ & $11.00 \pm 15.66$ & $13.88 \pm 19.35$ & $12.36 \pm 21.18$ & $9.77 \pm 13.59$ & 0.0001 \\
Monounsaturated to & $0.95 \pm 0.11$ & $1.12 \pm 0.29$ & $1.19 \pm 0.29$ & $1.27 \pm 0.50$ & $1.43 \pm 0.35$ & 0.0001 \\
saturated fat ratio & $2.21 \pm 1.25$ & $2.72 \pm 1.73$ & $3.31 \pm 1.78$ & $5.89 \pm 8.05$ & $9.92 \pm 10.05$ & 0.0001 \\
Fish & $18.93 \pm 9.03$ & $22.10 \pm 11.71$ & $19.28 \pm 11.00$ & $25.64 \pm 13.82$ & $38.72 \pm 31.36$ & 0.0001 \\
Red processed meat & $5.43 \pm 3.96$ & $8.97 \pm 6.34$ & $10.18 \pm 7.49$ & $13.25 \pm 7.91$ & $23.52 \pm 14.33$ & 0.0001 \\
Whole grains & $2.57 \pm 2.13$ & $6.01 \pm 4.51$ & $7.90 \pm 6.11$ & $9.82 \pm 5.86$ & $18.10 \pm 10.84$ & 0.0001 \\
Legumes & $8.57 \pm 3.84$ & $10.48 \pm 7.14$ & $13.41 \pm 8.48$ & $22.36 \pm 17.64$ & $32.95 \pm 21.29$ & 0.0001 \\
Fruit & $20.79 \pm 8.22$ & $28.57 \pm 11.06$ & $36.69 \pm 11.78$ & $48.96 \pm 24.26$ & $76.87 \pm 47.37$ & 0.0001 \\
Vegetables & $1.93 \pm 1.38$ & $2.70 \pm 1.98$ & $4.08 \pm 3.19$ & $4.08 \pm 3.19$ & $9.40 \pm 6.45$ & \\
Nuts & &
\end{tabular}

* ANOVA; comparison across groups Post hoc Tukey's b tests are presented in the Supplementary Material.

\subsection{Intake of Nutrient Precursors of the Intestinal Metabolites}

Supplemental Table S1 shows the intake of nutrient precursors of the intestinal metabolites by quintiles of metabolite levels; Table S2 shows nutrient intakes by quintile of TMAO levels. Despite very large differences in the plasma concentrations by quintiles of the metabolites, in general there were no significant differences in the intake of dietary precursors. An exception was for intake of vegetables and vegetable protein: lower intake was associated with lower plasma concentrations of phenylsulfate.

\subsection{Renal Function and Plasma Levels of Intestinal Metabolites}

Table 3 shows plasma levels of the intestinal metabolites by quartiles of eGFR; they were increased significantly with even modest renal impairment.

Table 3. Plasma levels of the intestinal metabolites by tertiles of estimated glomerular filtration rate.

\begin{tabular}{|c|c|c|c|c|}
\hline \multirow{3}{*}{$\begin{array}{c}\text { Plasma Levels of } \\
\text { Metabolites }(\mu \mathrm{mol} / \mathrm{L})\end{array}$} & \multicolumn{4}{|c|}{ Tertiles of eGFR } \\
\hline & T1 & T2 & T3 & $p$ Value * \\
\hline & $<71$ & $71-86$ & $>87$ & $p$ value \\
\hline TMAO & $5.10 \pm 8.08$ & $3.45 \pm 5.93$ & $2.30 \pm 5.83$ & 0.02 \\
\hline P-cresyl sulfate & $63.19 \pm 38.26$ & $40.44 \pm 23.80$ & $29.37 \pm 178.11$ & 0.0001 \\
\hline Hippuric acid & $8.97 \pm 10.86$ & $5.47 \pm 6.20$ & $6.13 \pm 8.26$ & 0.024 \\
\hline Indoxyl sulfate & $9.93 \pm 7.0$ & $5.72 \pm 2.73$ & $4.26 \pm 2.08$ & 0.0001 \\
\hline P-cresyl glucuronide & $0.61 \pm 1.33$ & $0.27 \pm 0.27$ & $0.20 \pm 0.23$ & 0.002 \\
\hline Phenyl acetyl glutamine & $4.79 \pm 5.16$ & $2.47 \pm 1.76$ & $1.93 \pm 2.54$ & 0.0001 \\
\hline Phenyl sulfate & $7.10 \pm 9.24$ & $4.04 \pm 5.54$ & $3.07 \pm 3.10$ & 0.0001 \\
\hline
\end{tabular}

* ANOVA; comparison across groups; eGFR = estimated glomerular filtration rate, calculated by the CKD-Epi equations) Post hoc Tukey's b tests are presented in the Supplementary Material. TMAO = trimethylamine N-oxide 
3.4. Carotid Plaque Burden by Quartiles of Plasma Levels of Intestinal Metabolites

Figure 2 shows carotid plaque burden (total plaque area in $\mathrm{mm}^{2}$ ) by quartiles of plasma levels of the intestinal metabolites.

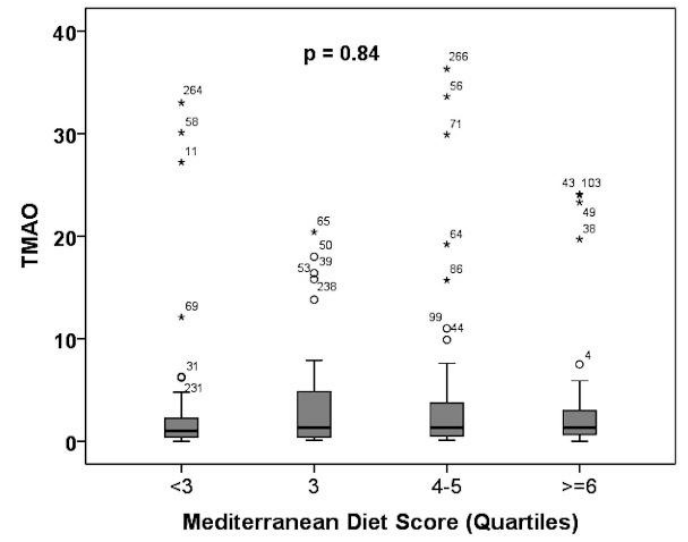

A

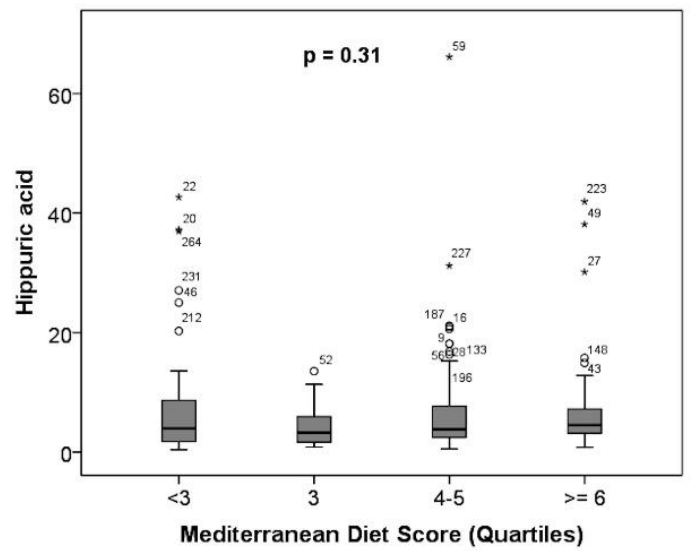

C

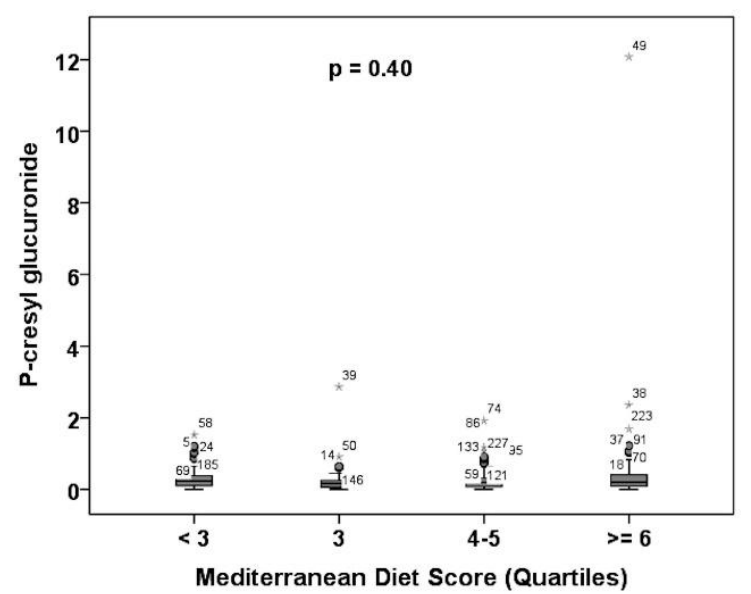

E

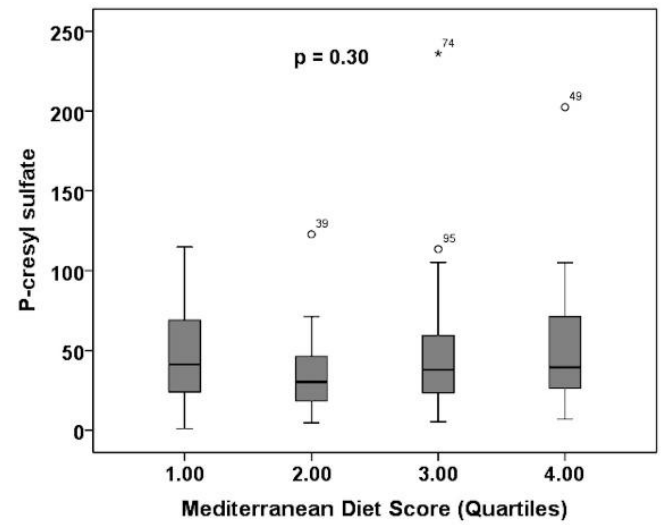

B

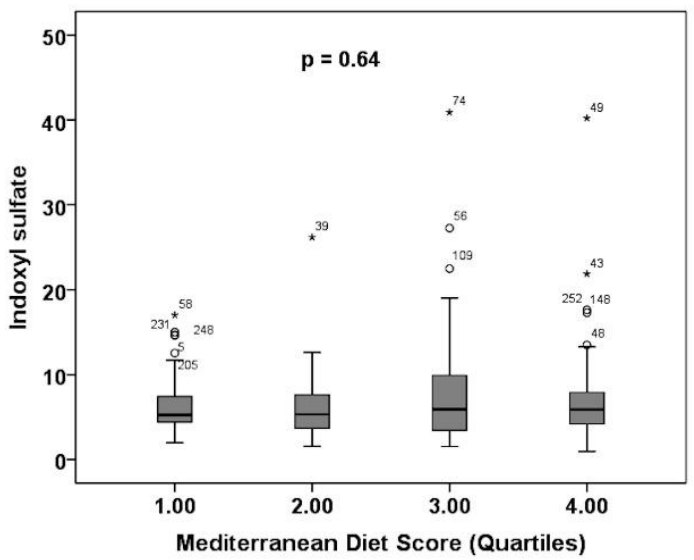

D

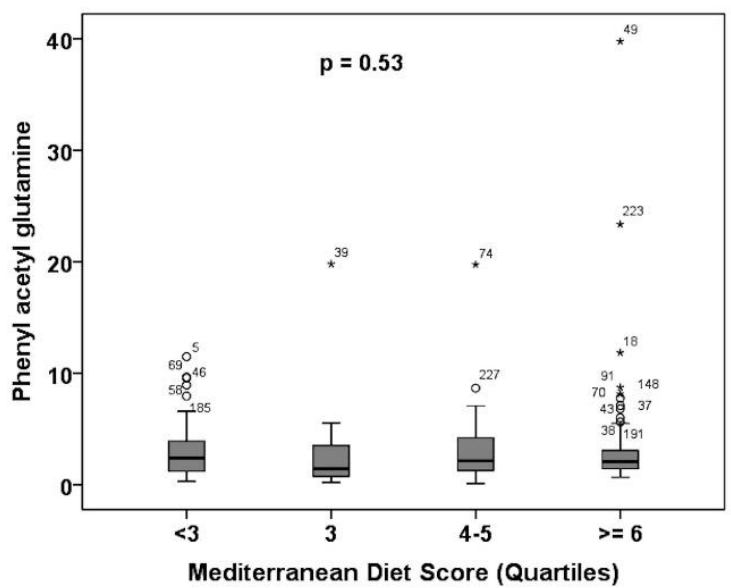

F

Figure 2. Cont. 


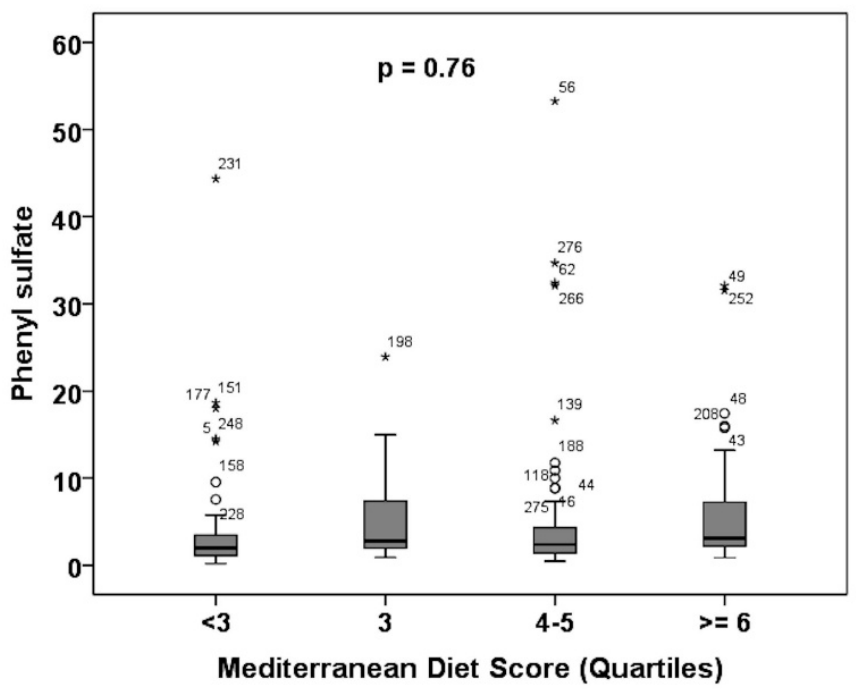

G

Figure 2. Carotid plaque burden is related to plasma levels of the intestinal metabolites. All the plasma levels are in $\mu \mathrm{mol} / \mathrm{L}$. TPA = total plaque area $\left(\mathrm{mm}^{2}\right)$. (A) Trimethylamine $\mathrm{N}$-oxide; (B) p-cresyl sulfate; (C) hippuric acid; (D) indoxyl sulfate; (E) p-cresyl glucuronide; (F) phenyl acetyl glutamine; and (G) phenyl sulfate. Differences were significant for trimethylamine $\mathrm{N}$-oxide $(p=0.004)$, p-cresyl sulfate $(p=0.001)$, and phenyl acetyl glutamine $p=0.0001){ }^{\circ}$ refers to outliers; ${ }^{*}$ refers to extreme outliers.

Figure 2 shows carotid plaque burden and plasma levels of the intestinal metabolites by quartiles of the Mediterranean diet score.

In this small sample we did not find any differences in the intestinal microbiome related to atherosclerosis severity or diet (submitted to Data in Brief as a companion article to a report in Atherosclerosis) [20].

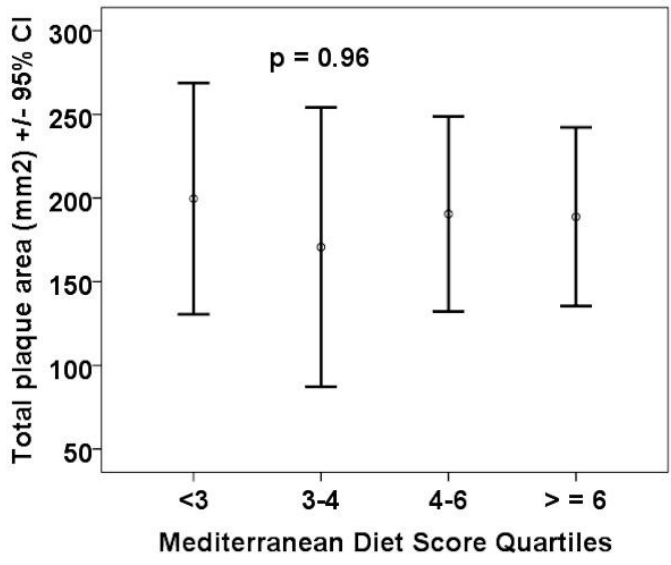

A

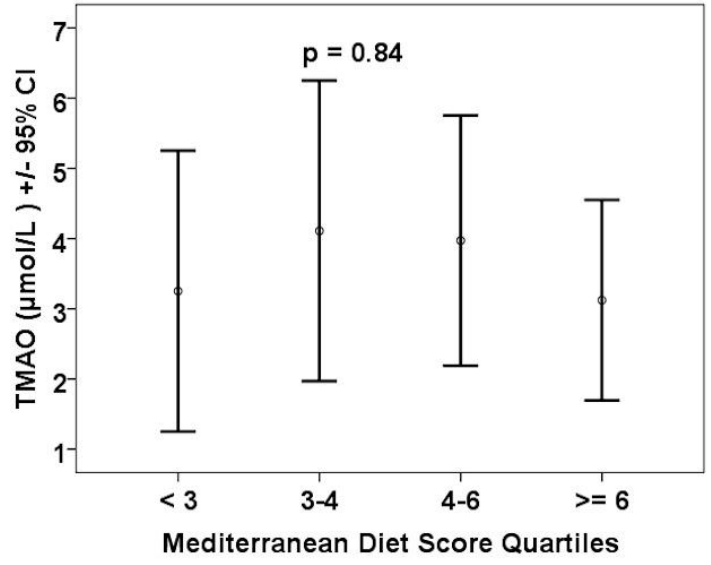

B 


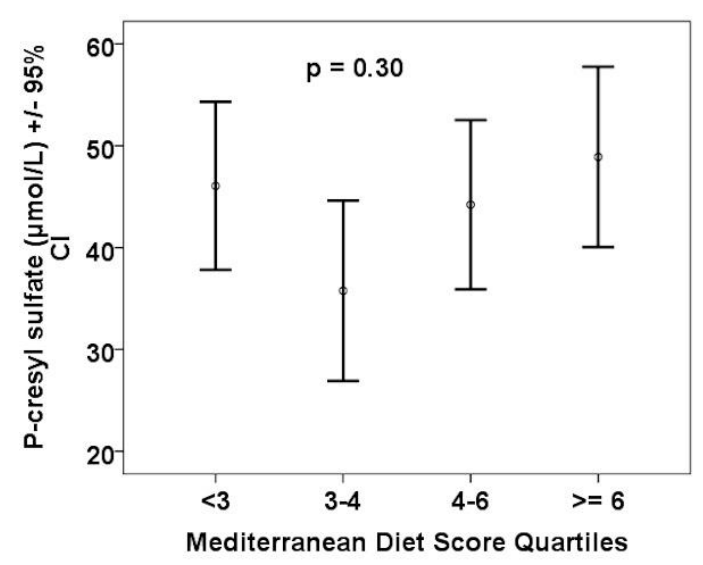

C

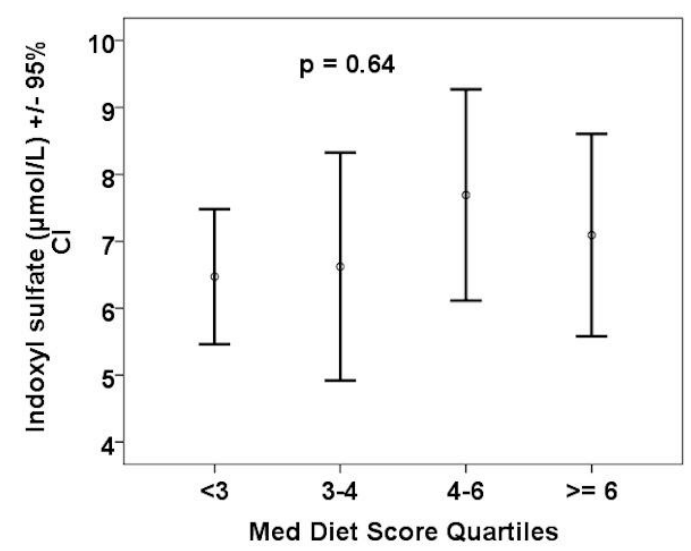

E

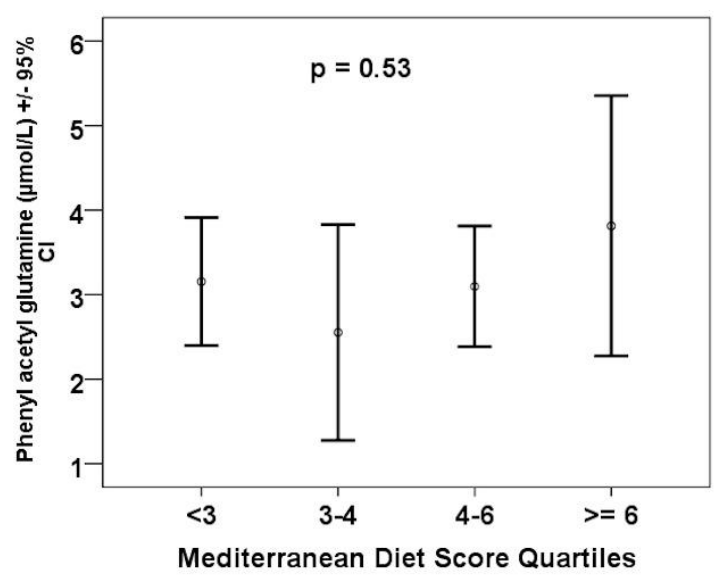

G

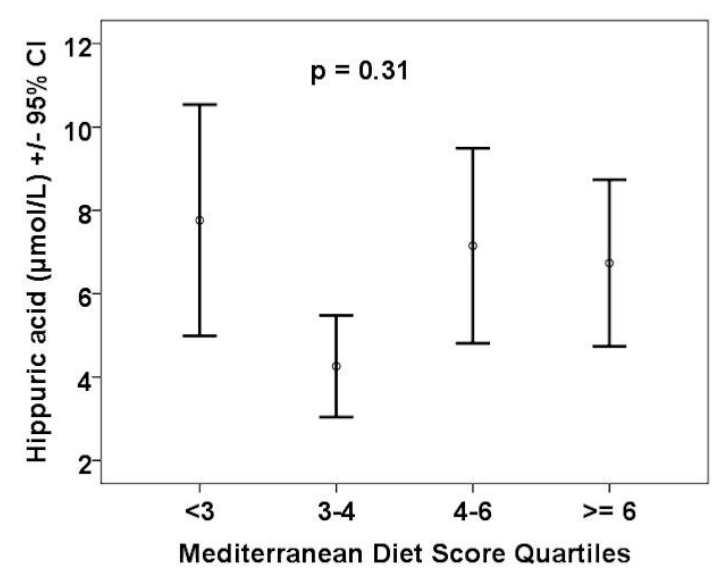

D

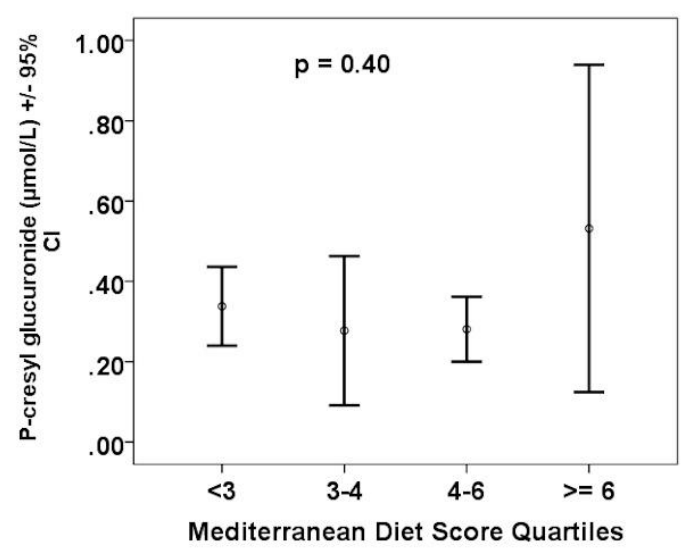

F

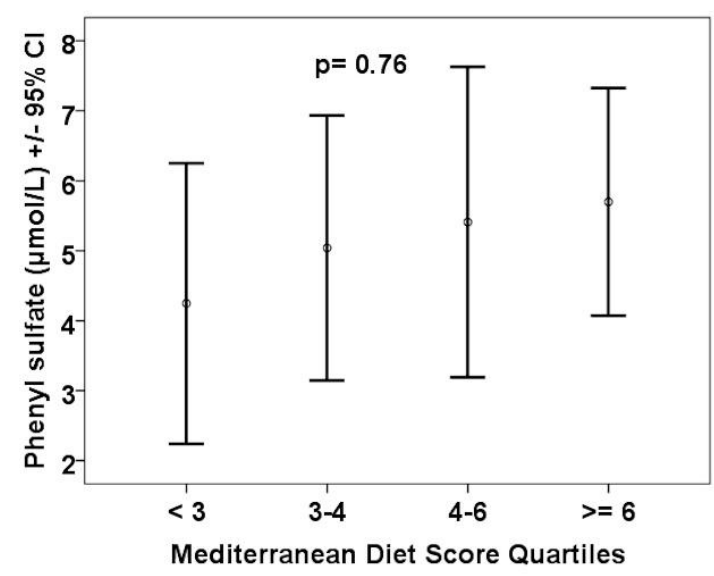

H

Figure 2. Carotid plaque burden and levels of intestinal metabolites by quartile of the Mediterranean diet score. Neither carotid plaque burden, nor the plasma levels of any of the metabolites, were significantly different by quartiles of the Mediterranean diet score. (A) Total plaque area $\left(\mathrm{mm}^{2}\right)$; (B) trimethylamine N-oxide; (C) p-cresyl sulfate; (D) hippuric acid; (E) indoxyl sulfate; (F) p-cresyl glucuronide; (G) phenyl acetyl glutamine; and $(\mathbf{H})$ phenyl sulfate. 


\section{Discussion}

We found that among omnivore vascular patients, neither the intake of specific nutrient precursors, nor the Mediterranean diet score predicted plasma levels of the intestinal metabolites. This suggests that it is the makeup of the intestinal microbiome that is the main determinant of the production of these metabolites. Even modestly impaired renal function resulted in significantly higher plasma levels of the metabolites, and carotid plaque burden was higher in patients with higher plasma levels of the intestinal metabolites. Renal impairment may also alter the intestinal flora [37]. In our study, renal function was better than in most earlier studies relating to the intestinal metabolites. In the study of Tang et al. [8], in which it was reported that high levels of TMAO accelerated decline of renal function and increased cardiovascular risk, the participants had an estimated glomerular filtration rate (eGFR) $<60$. In the study of Stubbs et al. [38], elevated levels of TMAO were seen only in participants with advanced kidney disease. In the present study, carotid plaque burden was not related significantly to the Mediterranean diet score.

Some studies have reported an effect of the Mediterranean diet on the intestinal microbiome $[39,40]$. De Filippis et al. studied 51 vegans, 51 vegetarians, and 51 omnivores, of which $30 \%$ had a high adherence to a Mediterranean diet. They found differences in plasma levels of fatty acids, and vegans and vegetarians had lower plasma levels of TMAO. Mitsou et al. [39] studied 120 Greek persons and found differences in some bacteria and in features of stool and bowel habits, but did not study intestinal metabolites. Perhaps our results were different because we studied patients with severe atherosclerosis, none of our study participants was vegan or strictly vegetarian, and few had high adherence to the Mediterranean diet.

An important limitation of our study was that the plasma levels of the metabolites were measured in the fasting state. In the study of Tang et al. in patients referred for coronary angiography, plasma levels of TMAO were measured after a test dose of two hard-boiled eggs [7] (containing $500 \mathrm{mg}$ of phosphatidylcholine); they reported that plasma TMAO increased for $\sim 8 \mathrm{~h}$ after consuming egg yolk. Miller et al. [41] reported a steep dose-response relationship between egg consumption and plasma TMAO. A major limitation was that our study was cross-sectional; ideally patients would be crossed over in random sequence from usual diet to a Mediterranean diet and vice-versa. Another important limitation of our study is that there were no vegans in our patient population; it would be important to study the questions we addressed in this study in vegans. Also, we had no data on physical activity, which may be associated with the benefits of the Mediterranean diet. High-level adherence to a Mediterranean diet has been reported to have beneficial effects on the intestinal microbiome [40], however in our study only three participants achieved the highest Mediterranean diet score of 8; the median score in the top quintile of Mediterranean diet score was 6 . Nevertheless, this level of adherence is probably better than that of the average North American. The American Heart Association reported in 2015 that $91.6 \%$ of Americans follow a poor diet, only $0.1 \%$ follow a healthy diet, and only $8.3 \%$ follow an intermediate diet [42]. This highlights the challenges of persuading vascular patients, many of whom have followed a poor diet all their life, to adhere to a healthy diet. A possible factor is the cost of fresh fruits and vegetables, and olive oil.

Levels of TMAO can be reduced by inhibitors of flavin monooxygenase 3, the enzyme responsible for oxidation of trimethylamine to TMAO [43,44], but this may not mitigate the effects of other intestinal metabolites. In patients with renal failure, broader approaches to reducing levels of intestinal metabolites could include more intensive dialysis, and renal transplantation. Probiotics and prebiotics may be feasible approaches to treatment of this problem, particularly if strains can impact directly or indirectly these compounds. The ability of strains to affect serum cholesterol is an example of such activity [45]. Fecal transplantation, or implantation of a selected panel of benign microbes (as used to treat Clostridiodes difficile $[46,47])$ present possible novel approaches to treatment of atherosclerosis. 


\section{Conclusions}

Even moderately impaired renal function was associated with significantly higher plasma levels of the intestinal metabolites, and carotid plaque burden was significantly higher in patients with higher plasma levels. Carotid plaque burden was not related to Mediterranean diet scores. Neither the intake of specific nutrient precursors nor the Mediterranean diet score significantly predicted plasma levels of the intestinal metabolites among omnivorous vascular patients. Other approaches to reduce the impact of the intestinal microbiome on cardiovascular disease may be required. These might include probiotics, prebiotics, or transplantation of stool or panels of beneficial bacteria.

Supplementary Materials: The following are available online at http:/ / www.mdpi.com/2072-6643/10/6/779/s1, Table S1: Intake of dietary precursors by quintiles of metabolite levels, Table S2: Nutrient intakes by quintile of TMAO levels.

Author Contributions: J.D.S., G.B.G., E.A.-V. and G.R. designed the study and obtained funding; M.P. and C.J. analyzed the nutritional data; C.B. recruited the patients and collected the data; B.L.U., K.N.R. and T.J.V. developed new analytical methods for the metabolites, measured the metabolites, and wrote the biochemical methods section; M.P. wrote initial drafts of the manuscript, and developed methods to calculate carnitine and pre-TMAO from the nutrient results; C.J. compiled the nutritional data and wrote initial draft of the nutritional methods, J.D.S. wrote revisions and had primary responsibility for final content; all authors contributed to revisions, and read and approved the final manuscript.

Funding: The study was partially funded by the Canadian Institutes of Health Research, Grant number 133416 (J.D.S., G.B.G., E.V.-A., G.R.).

Conflicts of Interest: Allen-Vercoe has published patents that describe the methods for preparation and use of cultured microbial communities for the treatment of intestinal diseases, and is cofounder of NuBiyota LLC, which was formed to promote commercialization of microbial ecosystem therapeutic products. None of the other authors has a conflict of interest.

\section{References}

1. Clemente, J.C.; Ursell, L.K.; Parfrey, L.W.; Knight, R. The impact of the gut microbiota on human health: An integrative view. Cell 2012, 148, 1258-1270. [CrossRef] [PubMed]

2. Spence, J.D. Effects of the intestinal microbiome on constituents of red meat and egg yolks: A new window opens on nutrition and cardiovascular disease. Can. J. Cardiol. 2014, 30, 150-151. [CrossRef] [PubMed]

3. Spence, J.D.; Urquhart, B.L.; Bang, H. Effect of renal impairment on atherosclerosis: Only partially mediated by homocysteine. Nephrol. Dial. Transplant. 2016, 31, 937-944. [CrossRef] [PubMed]

4. Cho, C.E.; Taesuwan, S.; Malysheva, O.V.; Bender, E.; Tulchinsky, N.F.; Yan, J.; Sutter, J.L.; Caudill, M.A. Trimethylamine- $N$-oxide (TMAO) response to animal source foods varies among healthy young men and is influenced by their gut microbiota composition: A randomized controlled trial. Mol. Nutr. Food Res. 2017, 61. [CrossRef] [PubMed]

5. Wang, Z.; Klipfell, E.; Bennett, B.J.; Koeth, R.; Levison, B.S.; Dugar, B.; Feldstein, A.E.; Britt, E.B.; Fu, X.; Chung, Y.M.; et al. Gut flora metabolism of phosphatidylcholine promotes cardiovascular disease. Nature 2011, 472, 57-63. [CrossRef] [PubMed]

6. Koeth, R.A.; Wang, Z.; Levison, B.S.; Buffa, J.A.; Org, E.; Sheehy, B.T.; Britt, E.B.; Fu, X.; Wu, Y.; Li, L.; et al. Intestinal microbiota metabolism of L-carnitine, a nutrient in red meat, promotes atherosclerosis. Nat. Med. 2013, 19, 576-585. [CrossRef] [PubMed]

7. Tang, W.H.W.; Wang, Z.; Levinson, B.S.; Koeth, R.A.; Britt, E.B.; Fu, X.; Wu, Y.; Hazen, S.L. Intestinal microbiota metabolism of phosphatidylcholine and cardiovascular risk. N. Engl. J. Med. 2013, 368, 1575-1584. [CrossRef] [PubMed]

8. Tang, W.H.; Wang, Z.; Kennedy, D.J.; Wu, Y.; Buffa, J.A.; Agatisa-Boyle, B.; Li, X.S.; Levison, B.S.; Hazen, S.L. Gut microbiota-dependent trimethylamine $\mathrm{N}$-oxide (tmao) pathway contributes to both development of renal insufficiency and mortality risk in chronic kidney disease. Circ. Res. 2015, 116, 448-455. [CrossRef] [PubMed]

9. Neirynck, N.; Glorieux, G.; Schepers, E.; Pletinck, A.; Dhondt, A.; Vanholder, R. Review of protein-bound toxins, possibility for blood purification therapy. Blood Purif. 2013, 35 (Suppl. 1), 45-50. [CrossRef] [PubMed] 
10. Sirich, T.L.; Funk, B.A.; Plummer, N.S.; Hostetter, T.H.; Meyer, T.W. Prominent accumulation in hemodialysis patients of solutes normally cleared by tubular secretion. J. Am. Soc. Nephrol. 2014, 25, 615-622. [CrossRef] [PubMed]

11. Barreto, F.C.; Barreto, D.V.; Liabeuf, S.; Meert, N.; Glorieux, G.; Temmar, M.; Choukroun, G.; Vanholder, R.; Massy, Z.A. Serum indoxyl sulfate is associated with vascular disease and mortality in chronic kidney disease patients. Clin. J. Am. Soc. Nephrol. 2009, 4, 1551-1558. [CrossRef] [PubMed]

12. Liabeuf, S.; Barreto, D.V.; Barreto, F.C.; Meert, N.; Glorieux, G.; Schepers, E.; Temmar, M.; Choukroun, G.; Vanholder, R.; Massy, Z.A. Free $p$-cresylsulphate is a predictor of mortality in patients at different stages of chronic kidney disease. Nephrol. Dial. Transplant. 2010, 25, 1183-1191. [CrossRef] [PubMed]

13. Meijers, B.K.; Bammens, B.; De Moor, B.; Verbeke, K.; Vanrenterghem, Y.; Evenepoel, P. Free $p$-cresol is associated with cardiovascular disease in hemodialysis patients. Kidney Int. 2008, 73, 1174-1180. [CrossRef] [PubMed]

14. Poesen, R.; Claes, K.; Evenepoel, P.; de Loor, H.; Augustijns, P.; Kuypers, D.; Meijers, B. Microbiota-derived phenylacetylglutamine associates with overall mortality and cardiovascular disease in patients with CKD. J. Am. Soc. Nephrol. 2016, 27, 3479-3487. [CrossRef] [PubMed]

15. Dou, L.; Jourde-Chiche, N.; Faure, V.; Cerini, C.; Berland, Y.; Dignat-George, F.; Brunet, P. The uremic solute indoxyl sulfate induces oxidative stress in endothelial cells. J. Thromb. Haemost. 2007, 5, 1302-1308. [CrossRef] [PubMed]

16. Dou, L.; Sallee, M.; Cerini, C.; Poitevin, S.; Gondouin, B.; Jourde-Chiche, N.; Fallague, K.; Brunet, P.; Calaf, R.; Dussol, B.; et al. The cardiovascular effect of the uremic solute indole-3 acetic acid. J. Am. Soc. Nephrol. 2015, 26, 876-887. [CrossRef] [PubMed]

17. Willett, W.C.; Stampfer, M.J. Rebuild the food pyramid. Sci. Am. 2003, 288, 64-71. [CrossRef] [PubMed]

18. Keys, A. Mediterranean diet and public health: Personal reflections. Am. J. Clin. Nutr. 1995, 61, 1321S-1323S. [CrossRef] [PubMed]

19. Stroke Prevention \& Atherosclerosis Research Centre (SPARC). Available online: http://www.imaging. robarts.ca/SPARC/ (accessed on 15 June 2018).

20. Bogiatzi, C.; Gloor, G.; Allen-Vercoe, E.; Reid, G.; Wong, R.G.; Urquhart, B.L.; Dinculescu, V.; Ruetz, K.N.; Velenosi, T.J.; Pignanelli, M.; et al. Metabolic products of the intestinal microbiome and extremes of atherosclerosis. Atherosclerosis 2018, 273, 91-97. [CrossRef] [PubMed]

21. Yuan, C.; Spiegelman, D.; Rimm, E.B.; Rosner, B.A.; Stampfer, M.J.; Barnett, J.B.; Chavarro, J.E.; Subar, A.F.; Sampson, L.K.; Willett, W.C. Validity of a dietary questionnaire assessed by comparison with multiple weighed dietary records or 24-hour recalls. Am. J. Epidemiol. 2017, 185, 570-584. [CrossRef] [PubMed]

22. Yuan, C.; Spiegelman, D.; Rimm, E.B.; Rosner, B.A.; Stampfer, M.J.; Barnett, J.B.; Chavarro, J.E.; Rood, J.C.; Harnack, L.J.; Sampson, L.K.; et al. Relative validity of nutrient intakes assessed by questionnaire, 24-hour recalls, and diet records compared with urinary recovery and plasma concentration biomarkers: Findings for women. Am. J. Epidemiol. 2018, 187, 1051-1063. [CrossRef] [PubMed]

23. Fung, T.T.; Pan, A.; Hou, T.; Mozaffarian, D.; Rexrode, K.M.; Willett, W.C.; Hu, F.B. Food quality score and the risk of coronary artery disease: A prospective analysis in 3 cohorts. Am. J. Clin. Nutr. 2016, 104, 65-72. [CrossRef] [PubMed]

24. Willett, W. Nutritional Epidemiology; Oxford University Press: New York, NY, USA, 1998.

25. USDA National Nutrient Database for Standard Reference and the USDA Branded Food Products Database. Available online: https:/ /www.ars.usda.gov/northeast-area/beltsville-md-bhnrc/beltsvillehuman-nutrition-research-center/nutrient-data-laboratory/ (accessed on 15 June 2018).

26. Fung, T.T.; Rexrode, K.M.; Mantzoros, C.S.; Manson, J.E.; Willett, W.C.; Hu, F.B. Mediterranean diet and incidence of and mortality from coronary heart disease and stroke in women. Circulation 2009, 119, 1093-1100. [CrossRef] [PubMed]

27. Trichopoulou, A.; Costacou, T.; Bamia, C.; Trichopoulos, D. Adherence to a mediterranean diet and survival in a Greek population. N. Engl. J. Med. 2003, 348, 2599-2608. [CrossRef] [PubMed]

28. Prosky, L.; Asp, N.G.; Furda, I.; DeVries, J.W.; Schweizer, T.F.; Harland, B.F. Determination of total dietary fiber in foods and food products: Collaborative study. J. Assoc. Off. Anal. Chem. 1985, 68, 677-679. [PubMed]

29. Kris-Etherton, P.M.; Harris, W.S.; Appel, L.J.; American Heart Association Nutrition Committee. Fish consumption, fish oil, omega-3 fatty acids, and cardiovascular disease. Circulation 2002, 106, 2747-2757. [CrossRef] [PubMed] 
30. Lombard, K.A.; Olson, A.L.; Nelson, S.E.; Rebouche, C.J. Carnitine status of lactoovovegetarians and strict vegetarian adults and children. Am. J. Clin. Nutr. 1989, 50, 301-306. [CrossRef] [PubMed]

31. Demarquoy, J.; Georges, B.; Rigault, C.; Royer, M.-C.; Clairet, A.; Soty, M.; Lekounoungou, S.; Le Borgne, F. Radioisotopic determination of L-carnitine content in foods commonly eaten in western countries. Food Chem. 2004, 86, 137-142. [CrossRef]

32. Higdon, J.; Drake, V.J.; Hagen, T.M. L-Carnitine. Available online: http://lpi.oregonstate.edu/mic/dietaryfactors /L-carnitine (accessed on 5 July 2017).

33. Heaney, L.M.; Jones, D.J.; Mbasu, R.J.; Ng, L.L.; Suzuki, T. High mass accuracy assay for trimethylamine N-oxide using stable-isotope dilution with liquid chromatography coupled to orthogonal acceleration time of flight mass spectrometry with multiple reaction monitoring. Anal. Bioanal. Chem. 2016, 408, 797-804. [CrossRef] [PubMed]

34. Ocque, A.J.; Stubbs, J.R.; Nolin, T.D. Development and validation of a simple uhplc-ms/ms method for the simultaneous determination of trimethylamine $N$-oxide, choline, and betaine in human plasma and urine. J. Pharm. Biomed. Anal. 2015, 109, 128-135. [CrossRef] [PubMed]

35. Velenosi, T.J.; Hennop, A.; Feere, D.A.; Tieu, A.; Kucey, A.S.; Kyriacou, P.; McCuaig, L.E.; Nevison, S.E.; Kerr, M.A.; Urquhart, B.L. Untargeted plasma and tissue metabolomics in rats with chronic kidney disease given AST-120. Sci. Rep. 2016, 6. [CrossRef] [PubMed]

36. Spence, J.D.; Eliasziw, M.; DiCicco, M.; Hackam, D.G.; Galil, R.; Lohmann, T. Carotid plaque area: A tool for targeting and evaluating vascular preventive therapy. Stroke 2002, 33, 2916-2922. [CrossRef] [PubMed]

37. Vaziri, N.D.; Wong, J.; Pahl, M.; Piceno, Y.M.; Yuan, J.; DeSantis, T.Z.; Ni, Z.; Nguyen, T.H.; Andersen, G.L. Chronic kidney disease alters intestinal microbial flora. Kidney Int. 2013, 83, 308-315. [CrossRef] [PubMed]

38. Stubbs, J.R.; House, J.A.; Ocque, A.J.; Zhang, S.; Johnson, C.; Kimber, C.; Schmidt, K.; Gupta, A.; Wetmore, J.B.; Nolin, T.D.; et al. Serum trimethylamine- $N$-oxide is elevated in CKD and correlates with coronary atherosclerosis burden. J. Am. Soc. Nephrol. 2016, 27, 305-313. [CrossRef] [PubMed]

39. Mitsou, E.K.; Kakali, A.; Antonopoulou, S.; Mountzouris, K.C.; Yannakoulia, M.; Panagiotakos, D.B.; Kyriacou, A. Adherence to the mediterranean diet is associated with the gut microbiota pattern and gastrointestinal characteristics in an adult population. Br. J. Nutr. 2017, 117, 1645-1655. [CrossRef] [PubMed]

40. De Filippis, F.; Pellegrini, N.; Vannini, L.; Jeffery, I.B.; La Storia, A.; Laghi, L.; Serrazanetti, D.I.; Di Cagno, R.; Ferrocino, I.; Lazzi, C.; et al. High-level adherence to a mediterranean diet beneficially impacts the gut microbiota and associated metabolome. Gut 2016, 65, 1812-1821. [CrossRef] [PubMed]

41. Miller, C.A.; Corbin, K.D.; da Costa, K.A.; Zhang, S.; Zhao, X.; Galanko, J.A.; Blevins, T.; Bennett, B.J.; O'Connor, A.; Zeisel, S.H. Effect of egg ingestion on trimethylamine- $N$-oxide production in humans: A randomized, controlled, dose-response study. Am. J. Clin. Nutr. 2014, 100, 778-786. [CrossRef] [PubMed]

42. Mozaffarian, D.; Benjamin, E.J.; Go, A.S.; Arnett, D.K.; Blaha, M.J.; Cushman, M.; de Ferranti, S.; Despres, J.P.; Fullerton, H.J.; Howard, V.J.; et al. Heart disease and stroke statistics-2015 update: A report from the american heart association. Circulation 2015, 131, e29-e322. [CrossRef] [PubMed]

43. Warrier, M.; Shih, D.M.; Burrows, A.C.; Ferguson, D.; Gromovsky, A.D.; Brown, A.L.; Marshall, S.; McDaniel, A.; Schugar, R.C.; Wang, Z.; et al. The TMAO-generating enzyme flavin monooxygenase 3 is a central regulator of cholesterol balance. Cell Rep. 2015, 10, 326-338. [CrossRef] [PubMed]

44. Wang, Z.; Roberts, A.B.; Buffa, J.A.; Levison, B.S.; Zhu, W.; Org, E.; Gu, X.; Huang, Y.; Zamanian-Daryoush, M.; Culley, M.K.; et al. Non-lethal inhibition of gut microbial trimethylamine production for the treatment of atherosclerosis. Cell 2015, 163, 1585-1595. [CrossRef] [PubMed]

45. Shimizu, M.; Hashiguchi, M.; Shiga, T.; Tamura, H.O.; Mochizuki, M. Meta-analysis: Effects of probiotic supplementation on lipid profiles in normal to mildly hypercholesterolemic individuals. PLoS ONE 2015, 10, e0139795. [CrossRef] [PubMed]

46. Gupta, S.; Allen-Vercoe, E.; Petrof, E.O. Fecal microbiota transplantation: In perspective. Ther. Adv. Gastroenterol. 2016, 9, 229-239. [CrossRef] [PubMed]

47. Petrof, E.O.; Gloor, G.B.; Vanner, S.J.; Weese, S.C.; Carter, D.; Daigneaul, M.C.; Brown, E.M.; Schroeter, K.; Allen-Vercoe, E. Stool substitute transplant therapy for the eradication of Clostridium difficile infection: 'Repoopulating' the gut. Microbiome 2013, 1, 1-12. [CrossRef] [PubMed]

(C) 2018 by the authors. Licensee MDPI, Basel, Switzerland. This article is an open access article distributed under the terms and conditions of the Creative Commons Attribution (CC BY) license (http:/ / creativecommons.org/licenses/by/4.0/). 